\title{
SOME EFFECTS OF DEVELOPMENTAL CHANGES ON THE INDICES OF MALOCCLUSION
}

\author{
By Chester J. Summers, D.D.S., M.P.H.*
}

"Measurement . . . is more than the pedantic pursuit of a decimal place. Its vital and absorbing aspect emerges most clearly when it becomes a question of measuring something that has never been measured, or better still, something that has been held unmeasurable." (S. S. Stevens)

The assessment of the prevalence of disease has been accepted as an integral part of the activities of public health. In order to assess such prevalence, tools for measuring the degree as well as the absence or presence become essential. One of the most common tools employed has been the disease-index.

In dental public health, the absolute prevalence of malocclusion still remains unknown. Many investigators $1,2,3,4,5$ have attempted, however, to describe the prevalence of malocclusion by the use of various methods of measurement (indices). When the scores from these indices have been plotted against time, that is, against the ages of the group of individuals under investigation, fluctuations usually were observed. One of these indices has been selected as an example to demonstrate the fluctuations. This index contained measurements that had been utilized in other indices of malocclusion and it also seemed to be the most popular, yet the most misused, index of malocclusion. It was proposed by Draker $^{1}$ in 1958, and was called the Handicapping Labio-lingual Deviations (HLD Index).

When the HLD Index first was described, a definite distinction was made between the concepts of malocclusion and orthodontic handicap. As Draker stated, a malocclusion implies a diagnosis, a process achieved by consideration of the etiology and a differential diagnosis. An orthodontic handicap was defined from a statement developed at the White House Conference on Child Health and Protection": "A sound principle would seem to be to try to establish empirically the point, with respect to each trait under consideration, at which some definite handicap or dysfunction begins to be associated with extreme variation."

"An extreme deviation from the 'norm' is, therefore, considered a handicap," continued Draker. Summarizing, he stated that "labio-lingual deviations from a fictitious norm rather than the state of occlusion are of epidemiological importance in establishing prevalence for physically handicapping orthodontic defects, and the degree of the physical handicap." Draker, then, concluded that the HLD Index could be used to measure, not only the point where extreme variation began as an orthodontic handicap, but also to measure the degree of such handicap.

Even though Draker stated that the HLD Index could not measure malocclusion, the measurement of malocclusion by the HLD Index apparently was implied by others. ${ }^{7}, 8,9,10$

\footnotetext{
* Trainee in General Epidemiology, School of Public Health, The University of Michigan, Ann Arbor, Michigan, supported by Grant No. GM-6-08 from the National Institute of General Medical Sciences, National Institutes of Health.
} 


\section{Purposes and Scope}

The purposes of the report, now to be presented, will be (1) to develop a concept of measuring malocclusion that considers developmental changes; and (2) use of this concept as an hypothesis to test an example of an index of malocclusion for its validity.

An index now may be defined as an instrument which can measure the degree of a condition that is in existence. An index should be quantitative, since it must indicate the severity of the condition with reasonable accuracy, and should be suitable for statistical evaluation. One of the main requirements of an index is that it possess validity. Validity may be defined as the extent to which differences in scores reflect true differences among individuals, groups, or situations in the characteristic for which measurement is sought, or true differences in the same individual, group or situation from once occasion to another, in contrast to constant or random errors. Simply stated, validity must exist as the ability of a test (index) to provide a true measurement of the item being tested.

One of the methods that has been used to test the validity of an index has been the determination of the consistency of the measurements over a period of time. To do so, one must obtain measurements of the same subject at regular intervals of time and, using the same index, then compare the scores. In theory, the scores should be expected either to remain unchanged, which would indicate that the malocclusion was the same at all ages, or would show a continual increase or decrease which would indicate that the malocclusion got worse or that the malocclussion got better as the subject increased in age. This theory has been demonstrated graphically. (Fig. 1).

Figure 1

THE (THEORETICAL) CHANGE IN THE DEGREE OF MALOCCLUSION
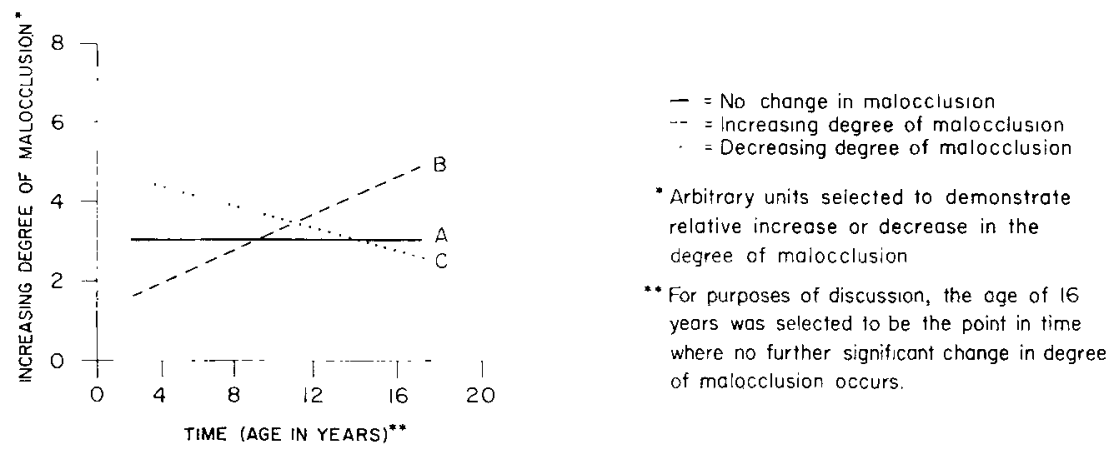

In order to measure malocclusion with validity, the index must consider developmental (or growth) changes. Since developmental changes in malocclusion may consist either of a basic orthodontic defect or a symptom of a developmental change, an index of malocclusion must concentrate on, and be sensitive to the basic orthodontic defect, and not unduly sensitive to the symptom.

A basic orthodontic defect may be defined as a constant occlusal dysfunction which may exist before, during and after the development of occlusion. This defect may be: (1) skeletal (such as a mandible disproportionate in size to the maxilla); (2) dental (such as a discrepancy in the size of the teeth and the 
jaw); or (3) neuromuscular (such as tongue thrusting). The basic orthodontic defect usually is present before the development of occlusion, although it may not become manifest until after the stage of the mixed dentition. As an example, a skeletal Class II malocclusion at age seven is still a skeletal Class II malocclusion at age 16, yet it was present at age two. A basic orthodontic defect, then, will be more likely to follow lines A or B in Figure 1.

A symptom of a developmental change may be defined an an adaptation to development; this change may be either an accommodation to normal growth or to a basic orthodontic defect. The symptom may either be constant (present at all ages) or variable (fluctuate with age). An example of a symptom is the flaring and spacing of the maxillary permament incisors normally seen in the early mixed dentition. A symptom, then, may follow lines A, B or C in Figure 1 , either separately (constant) or in combination (variable).

Considering the concept of developmental change and its relation to malocclusion, the hyopthesis used to evaluate the validity of an index of malocclusion now may be stated: "Malocclusion, if present, must be measured in terms of the basic orthodontic defect; the degree of malocclusion, then, either remains the same over time with no significant change (Line A, Fig. 1), or increases over time, that is, the malocclusion gets worse (Line B, Fig. 1)."

It should be noted that this hypothesis excluded a decreasing degree of malocclusion (Line C, Fig. 1). A decrease in the degree of malocclusion would not be typical of basic orthodontic defects. Basic orthodontic defects rarely are self-corrective. It is the symptoms which change; the basic orthodontic defect persists. For example, a Class II occlusion with a moderate overjet may reduce to a Class II occlusion with a mild overjet; the symptom improved but the Class II occlusion remained. An index of malocclusion may be considered more desirable, therefore, if its scores remain the same or increase over time, since the index probably will be measuring the basic orthodontic defect rather than the symptom. Similarly, serious handicapping occlusions also should be measured in terms of the basic orthodontic defect, since the defect usually is the cause of the handicap.

\section{Method of Study}

A collection of serial dentofacial data (in the form of casts) was made available from The University of Michigan's Growth Study.*

The following criteria were used to select an individual's set of casts: (1) The set must contain annual casts from the same individual, beginning with (at least) the sixth year of age to (at least) the fifteenth year of age; and (2) no orthodontic treatment had been rendered to any of the subjects.

Thirty-five subjects were found who met these criteria, 20 males and 15 females. Each cast for each subject was measured according to the HLD Index. A sample data-sheet may be viewed (Figure 2). The total score of the HLD Index on each cast of each subject was determined, sorted by age and averaged. The average HLD Index score, by age, from the same subjects may be viewed (Figure 3).

* The University of Michigan's Growth Study includes a collection of physical and mental clata on growth, recorded annually on students attending the University Elementary and High Schools. The dentofacial clata consist of casts and cephalographs from over 400 of these students. 
Figure 2

HLD INDEX STUDY - SAMPLE DATA SHEET

NAME SEX

CASE NUMBER

DATE OF BIRTH

\begin{tabular}{|c|c|c|c|c|c|c|c|c|c|}
\hline \multicolumn{2}{|c|}{ MEASUREMENT: } & 1 & 2 & 3 & 4 & 5 & 6 & 7 & \\
\hline AGE & $\begin{array}{c}\text { MIXED } \\
\text { DENTITION } \\
\text { PRESENT }\end{array}$ & $\begin{array}{l}\text { CLFFT } \\
\text { PALATE }\end{array}$ & $\begin{array}{l}\text { TRAUMATIC } \\
\text { DEVIATION }\end{array}$ & OVERJET & OVERBITE & $\begin{array}{l}\text { MANDIBULAR } \\
\text { PROTRUSION }\end{array}$ & $\begin{array}{l}\text { OPEN } \\
\text { BITE }\end{array}$ & $\begin{array}{l}\text { LABIO- } \\
\text { LINGUAL } \\
\text { SPREAD }\end{array}$ & TOTAL \\
\hline 5 & & & & & & & & & \\
\hline 6 & & & & & & & & & \\
\hline 7 & & & & & & & & & \\
\hline 8 & & & & & & & & & \\
\hline 9 & & & & & & & & & \\
\hline 10 & & & & & & & & & \\
\hline 11 & & & & & & & & & \\
\hline 12 & & & & & & & & & \\
\hline 13 & & & & & & & & & \\
\hline 14 & & & & & & & & & \\
\hline 15 & & & & & & & & & \\
\hline 16 & & & & & & & & & \\
\hline
\end{tabular}

Figure 3

AVERAGE HLD INDEX SCORE BY AGE AND SEX,

FOR 20 MALE AND 15 FEMALE SUBJECTS, WHEN SERIAL DATA ARE USED

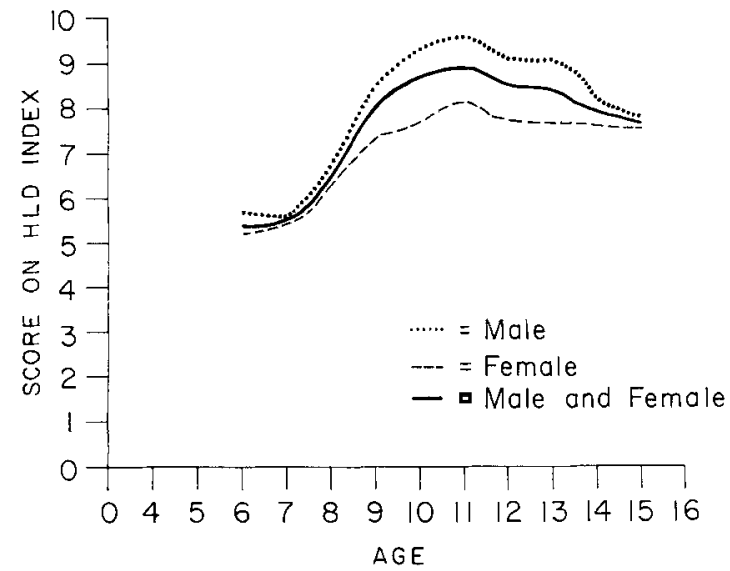

Discussion

None of the subjects had any evidence of a cleft palate or traumatic deviation ("malocclusions resulting from serious structural deformaties associated with growth and development of the mandible or maxilla."11) Draker's measurement, Nos. 1 and 2, were not considered, therefore. It would seem sufficient to state that any subject who had a cleft palate or a traumatic deviation would qualify for acceptance in the "New York State Dental Rehabilitation Program" even if other conditions were absent. Draker" originally scored such conditions 15 points. 
The discussion will include measurement Nos. 3, 4, 5, 6, and 7, that is, overjet, overbite, mandibular protrusion, openbite, and labio-lingual spread (deviation from "what would have been" a normal arch). A total score of " 13 " and over constituted a physical handicap, according to Draker.

A comparison of Figure 3 with Lines A and B, in Figure 1, will show, while the scores for the HLD Index increase from ages six to 11 , they decrease from ages 11 to 15 . Scores from the HLD Index were not constant as were those in Figure 1, Lines A or B. The scores of the HLD Index would seem to indicate an increase in the degree of "occlusal handicap" to age 11, after which the "occlusal handicap" decreased. One must question whether the HLD Index was weighted, therefore, to score the symptoms more heavily which change with age, than the basic orthodontic defect.

The similarity of Figure 3 to that of Figure 4, can be noted as an attempt to classify malocclusion subjectively by Moore, in 1948. ${ }^{13}$ Moore's classification of "Comprehensive Treatment," however, seemed to approach Line B, in Figure 1.

Figure 4

PERCENTAGES OF THE VARIOUS TYPES OF MALOCCLUSION AT ALL AGES, FROM 5 TO $17^{*}$

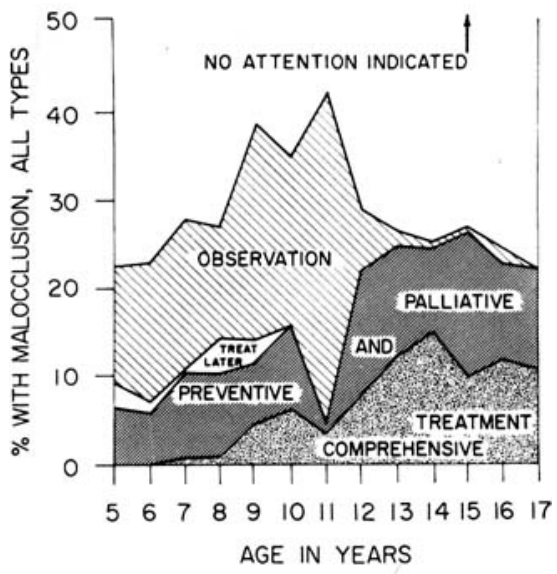

${ }^{*}$ Based on an original survey at Sturgis, Michigan, by Moore. ${ }^{17}$

The HLD Index usually has been recorded for children whose permanent anterior teeth have completed eruption by age 10 or 11 . Figure 3 shows that from ages 11 to 15 the average scores of the HLD Index decreased for both males and females, contrary to the hyopthesis that the scores of a valid index either should remain the same or increase with time.

Since the score at age 15 was determined in part by the score received at age 11, a "sign test" was used to determine the significance of the change from age 11 to 15 . In order to increase the size of the sample, 16 additional subjects who did not have all of the annual dental casts from the ages of six to 15 , but had casts for both ages 11 and 15, were added to the original sample.* Table 1 shows the change in the score of HLD Index from age 11 to 15 , by sex.

\footnotetext{
- Subjects who showed an increase in the score of the HLD Index from age 11 to 15 were classified as a plus ( + ); those who showed at decrease were classified as a minus ( $(-)$. A "no change" was classified as a plus $(+)$ because of the statement of the null $\left(\mathrm{H}_{6}\right)$ hypothesis.
} 
Table 1

CHANGE IN HLD INDEX SCORE

FROM AGE 11 TO 15

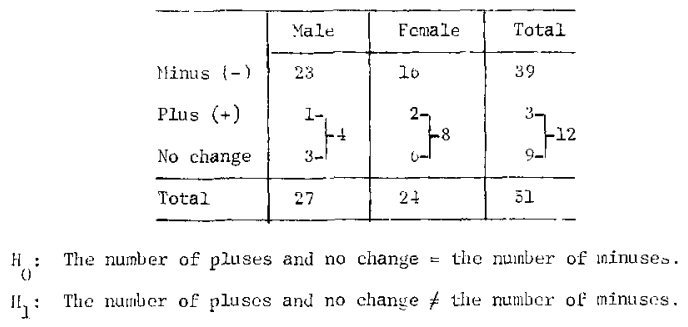

When approximated by the normal curve, the " $\mathrm{t}$ " value was -3.64 , which was significant at $0.01 . \mathrm{H}_{0}$ was rejected, therefore; $\mathrm{H}_{1}$ was accepted; there was a significant decrease in the scores of the HLD Index for ages 11 and 15.

The following analyses were based on the original 35 subjects:

A. When the HLD Index was broken into its component parts (measurement Nos. 3, 4, 5, 6, and 7), the measurement of overjet indicated the greatest change of all measurements for ages 11 and 15 .

when $\bar{x}=$ mean for age "n."

$$
\text { In males, } \begin{aligned}
\bar{x}_{11} & =4.85 \mathrm{~mm} . \\
\bar{x}_{15} & =3.98 \mathrm{~mm} .
\end{aligned}
$$

These values are in agreement with those of Bjork $^{13}$ who examined 243 Swedish males, age 12, and re-examined these same subjects at age 20. Bjork concluded that overjet decreased after age 12 .

$$
\text { Bjork's data: (Males) } \begin{aligned}
\overrightarrow{\mathrm{x}}_{12} & =4.1 \mathrm{~mm} . \\
\overrightarrow{\mathrm{x}}_{20} & =3.4 \mathrm{~mm} .
\end{aligned}
$$

It also should be stated that the overjet increased from ages six to 11 and then decreased to age 15 . This finding maintained for male and female subjects.

B. Overbite: From ages six to 12, overbite increased; from ages 13 to 15, overbite decreased. These findings are in agreement with those of Fleming ${ }^{14}$ who studied the vertical overbite of 28 subjects. These findings held true for both the male and female subjects.

C. Mandibular Protrusion: Two subjects, one male and one female, demonstrated mandibular protrusion at age six in the magnitude of one $\mathrm{mm}$. This condition, however, resolved itself into overjet after age nine.

D. Openbite: Seven subjects, five male and two female, demonstrated openbite in the magnitude of one to three $\mathrm{mm}$. at age six. This condition resolved itself into overbite after the subjects reached age nine. This finding agreed with Clinthorne's $\mathrm{s}^{15}$ who stated that the vertical overlap decreased from ages five to 10 by 70 to 29 percent in a study of 27 children who exhibited anterior openbite.

E. Labio-lingual spread: In both the male and female subjects labio-lingual spread increased from ages six to 10 and then decreased slowly from ages 11 to 15 .

\section{Additional Findings}

Fulton, ${ }^{16}$ in his study of "The Life Cycle of Human Teeth," investigated a stratified random sample of the population in North Carolina. Over 2,000 subjects, ages six to 15 , were included in a study in which the HLD Index was used. 
The findings, for males, ${ }^{*}$ were compared to the males in the sample from the University of Michigan's Growth Study in Figure 5. It can be noted that the average scores from both samples fluctuated over a period of time.

Figure 5

AVERAGE SCORE OF HLD INDEX FOR MALES BY AGE;

SAMPLE OF UNIVERSITY OF MICHIGAN'S GROWTH STUDY AND SAMPLE OF UNIVERSITY OF NORTH CAROLINA

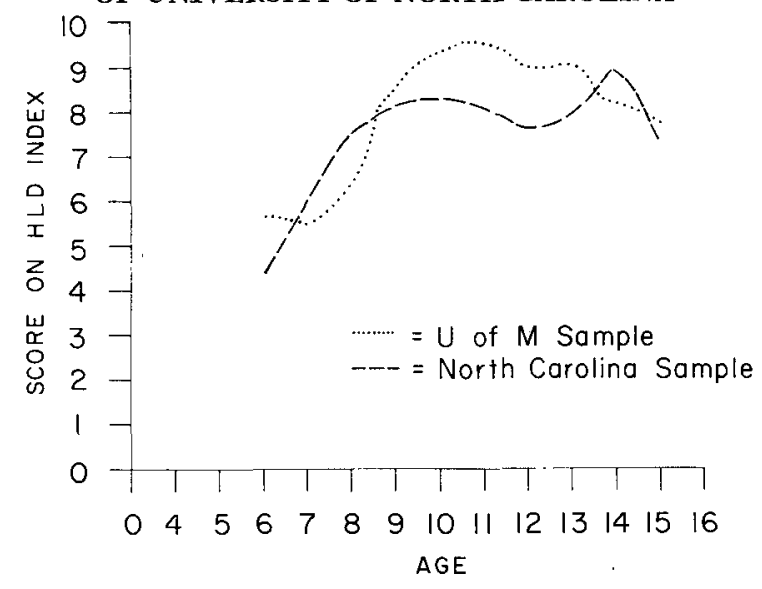

\section{Consideration of the HLD Index}

When scoring the measurements of the HLD Index, equal weights were given to each of the five measurements: overbite, overjet, openbite, mandibular protrusions, and labio-lingual spread. The total score was obtained by adding these measurements in millimeters. An overjet of five $\mathrm{mm}$. had the same total score (other measurements being " 0 ") as that of an openbite of five mm. (other measurements being " 0 "). The two, overjet and openbite, were not equal, since five $\mathrm{mm}$. of overjet was not considered to be of the same severity as that of five $\mathrm{mm}$. of openbite. The HLD Index, however, scored them the same.

The HLD Index also indicated that a subject with an end-to-end anterior relationship, that is, no overbite, overjet, mandibular protrusion, or openbite, had no occlusal handicap. It might be considered as "ideal," since the score of the HLD Index would be " 0 ." A subject with two $\mathrm{mm}$. of overbite and a two $\mathrm{mm}$. of overjet, however, might be considered more of the "ideal" than an end-toend anterior relationship. The HLD Index would score such a subject as " 4 ," and apparently would indicate that there was some tendency toward an occlusal handicap. This finding added another reason why the HLD Index should not be regarded as an index of malocclusion.

Since the five measurements of the HLD Index had equal weights and were added together, these measurements should be mutually exclusive. Considering openbite and overbite, it became obvious that a subject could not have both; the subject usually had one or the other, sometimes neither, but never both. The same situation became obvious for mandibular protrusion and overjet. In the HLD Index, there can be scores (other than " 0 ") in only three of the five measurements.

\footnotetext{
* The measurements were for white males only, but very little variation was found for sex or race. ${ }^{16}$
} 


\section{Summary}

The concepts of basic orthodontic defect and symptom of a developmental change were used to develop a hypothesis for testing the validity of an index of malocclusion. This hypothesis states: "Malocclusion, if present, must be measured in terms of the basic orthodontic defect; the degree of malocclusion, then, either remains the same over time with no significant change, or increases over time, that is, the malocclusion gets worse."

The test for validity was performed on an index of malocclusion, the HLD Index. The methods of testing for validity were outlined. The results showed that the average total score of 35 subjects decreased after age 11. This apparent decrease in degree of malocclusion was contrary to the hypothesis previously stated that most malocclusions either remained the same of got worse over time.

A consideration of the HLD Index was presented and the concepts of malocclusion and orthodontic handicap, as defined by Draker, were stated. The five measurements of the HLD Index were discussed and their weaknesses pointed out.

\section{CONCLUSIONS}

1. Because the basic orthodontic defect remains the same or worsens with time while its associated symptoms fluctuate, valid indices of malocclusion probably should be derived from the basic orthodontic defect itself.

2. Some of the difficulties encountered in devising a satisfactory index of malocclusion are:

a. The scores of the index remain the same or increase with time.

b. Individual weighting factors may be necessary.

c. Measurements should be mutually exclusive.

3. The HLD Index was intended to be used for the identification of serious handicapping occlusions and not as an index for assessing the degree of malocclusion.

\section{Bibliography}

1. Draker, H. L. Handicapping labio-lingual deviations: a proposed index for public health purposes. Bul. Pub. Health Dent., 18:1-17, Dec. 1958.

2. Massler, Maury, and Frankel, J. M. Prevalence of malocclusion in children aged 14 to 18 years. Am. J. Orthodont., 37:751-68, Oct. 1951.

3. Pelton, W. J., and Elsasser, W. A. Studies of dentofacial morphology. IV. Profile changes among 6,829 white individuals according to age and sex. Angle Orthodont., 25:199-207, Oct. 1955.

4. Poulton, D. R., and Aaronson, S. A. The relationship between occlusion and periodontal status. Am. J. Orthodont., 47:690-9, Sept. 1961.

5. Van Kirk, L. E., and Pennell, E. H. Assessment of malocclusion in population groups. Am. J. Pub. Health, 49:1157-63, Sept. 1959.

6. White House Conference on Child Health and Protection. Committee on growth and development. Growth and development of the child; general considerations. New York City, Century, 1932. XVIII + 377 pp. (p. 16)

7. Easlick, K. A., ed. The administration of local dental programs. Ann Arbor, University of Michigan School of Public Health Continued Education Service, c1963. VIII + 278 p. (p. 39).

8. Szwejda, L. F. The HLD Index by race and ingestion of fluoridated water. J. Pub. Health Dent., 25:2-6, Winter 1965.

9. Ast, D. B., Allaway, Normal, and Draker, H. L. The prevalence of malocclusion to dental caries and lost permanent molars, in a fluoridated city and a fluoride-deficient city. Am. J. Orthodont., 48:106-13, Feb. 1962.

10. Knutson, J. W. Status of orthodontics as a health service. Am. Dent. A. J., 70:1204-10, May 1965. 
11. Draker, H. L. Handicapping labio-lingual deviations: a proposed index for public health purposes. Am. J. Orthodont., 46:295-305, Apr. 1960.

12. Moore, G. R. The orthodontic program of the Michigan Department of Health with a new classification for survey. Am. J. Orthodont., 34:355-61, Apr. 1948.

13. Bjork, Arve. Variability and change in overjet and overbite. Am. J. Orthodont., 39:779801, Oct. 1953.

14. Fleming, H. B. An investigation of the vertical overbite during the eruption of the permanent dentition. Angle Orthodont., 31:53-62, Jan. 1961.

15. Clinthorne, H. N. A serial study of open bite. Ann Arbor, University of Michigan, School of Dentistry, $1965.40 \mathrm{p}$. typed thesis.

16. Fulton, J. T. Personal communication, June 1, 1965. (To be published as Edition 2 of the "Life Cycle of Human Teeth")

\title{
Opportunity
}

Think for a few minutes of the opportunities in your community and in your nation. Remember that you enjoy all of the liberties and freedoms of choice granted to Americans. Dentists, in fact, have even greater privileges than many in other vocations. They can choose to work long or short hours, charge high or low fees, employ personnel or not, and exercise many personal liberties unknown to most working men and women. (Robert R. Lacey in Bulletin of the New York State Society of Dentistry for Children, November 1965)

\section{CHANGES IN THE STATUS OF ORAL HEALTH AND ITS PRACTICE FOLLOWING A PROGRAM OF DENTAL HEALTH EDUCATION}

\author{
By Carl B. Holmes, D.D.S., M.P.H.*
}

Some tentative conclusions about the effectiveness of educating junior high school students in dental health. They await a more comprehensive study.

Health education has been defined as, "the translation of what is known about health into desirable patterns of health behavior by both individuals and communities through the educational process." Dental health education, then, is, "the focusing of educational efforts on an important aspect of total health ... dental health." A health educator is, "a person, be he dentist, physician, nurse, teacher, or other, who stimulates health understanding and action in the individual or community, for interest, study, and action toward the solution of health problems."1

\footnotetext{
* Associate Professor of Public Health Administration, School of Public Health, University of North Carolina, Chapel Hill, North Carolina.
} 